\title{
INFORME
}

\section{LOS ESTADOS DE EXCEPCIÓN EN TIEMPOS DE PANDEMIA: UN ESTUDIO COMPARADO EN AMÉRICA LATINA}

por Andrés Cervantes,

Abogado ${ }^{1}$

Mario Matarrita,

Abogado y criminólogo ${ }^{2}$

y Sofía Reca

Abogada $^{3}$

Cómo citar este artículo / Citation:

Cervantes, Andrés; Matarrita, Mario; y Reca, Sofía (2020):

Los estados de excepción en tiempos de pandemia:

un estudio comparado en América Latina, en:

Cuadernos Manuel Giménez Abad, nr. 20.

DOI: https://doi.org/10.47919/FMGA.CM20.0032

fundación

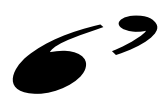

Manuel Giménez Abad deEstudios Parlamentarios ydelEstado Autonómico

\footnotetext{
1. Máster en ciencias jurídicas avanzadas y doctor en derecho por la Universidad Pompeu Fabra (UPF) (España). Máster en derecho constitucional por la Universitat de Valencia (España). Docente en la UPF y en la Universidad de Especialidades Espíritu Santo (Ecuador).

2. Candidato a doctor en derecho por la UPF y máster en justicia constitucional por la Universidad de Costa Rica (UCR). Diplomas de especialización en justicia constitucional, interpretación de la constitución y derecho internacional, respectivamente, por las universidades de Pisa (Italia), Castilla-La Mancha (España) y Heidelberg (Alemania). Docente en la UPF y UCR.

3. Candidata a doctora en derecho por la UPF. Máster en derecho constitucional por el Centro de Estudios Políticos y Constitucionales (España) y máster en derecho administrativo por la Universidad Austral (Argentina). Docente en la UPF.
} 


\title{
RESUMEN
}

La pandemia originada por el COVID-19 ha supuesto un punto de quiebre para el derecho constitucional global. Las medidas adoptadas por los estados para ralentizar el avance del virus van desde el confinamiento domiciliario, el cierre de fronteras, la suspensión general de actividades e, inclusive, medidas de rescate económico y social. En ese marco, el objeto del texto es doble. Por un lado, describe y analiza el marco constitucional de determinados países latinoamericanos que han decretado estado de excepción a efectos de identificar similitudes y diferencias en la reacción a la pandemia en curso. De otro lado, el texto informa sobre el contexto, las medidas adoptadas por cada país de la región y los mecanismos de control político-judicial en materia del derecho de excepción. Dado que la pandemia es un problema global que acarrea consecuencias a mediano y largo plazo, se vuelve imperativo fortalecer un marco de cooperación internacional que permita afrontar, en el futuro, ese tipo de amenazas de forma efectiva.

Palabras clave: Estados de excepción, COVID-19, América Latina, Derechos Humanos

\begin{abstract}
The pandemic caused by Covid-19 has meant a breaking point for global constitutional law. The measures adopted by the states to slow down the advance of the pandemic range from house confinement, the closing of borders, the general suspension of activities and even economic and social rescue measures. In this framework, the purpose of the text is twofold. On the one hand, it describes and analyzes the constitutional framework of some Latin American countries that have decreed a state of emergency in order to identify similarities and differences in the reaction to the ongoing pandemic. On the other hand, the text informs about the context, the measures adopted by each country in the region and the political-judicial control mechanisms regarding the right of exception. Given that the pandemic is a global problem that has consequences in the medium and long-term, it becomes imperative to strengthen an international cooperation framework that allows us to face such threats effectively in the future.
\end{abstract}

Key words: State of emergency, COVID-19, Latin America, Human rights 


\section{INTRODUCCIÓN}

Las Constituciones, como pacto político fundamental en materia de derechos y de organización de la vida en común, tienen vocación de permanencia en el tiempo ${ }^{4} \mathrm{y}$, por su medio, la sociedad busca construir un orden fundado en la estabilidad. Prueba de ello es que, en sus acepciones modernas, estos textos presentan un alto grado de rigidez y en su seno consta un catálogo de derechos fundamentales cuyo núcleo esencial queda extramuros a la acción legislativa.

Sin embargo, también es una verdad que, en su estado actual, una inmensa mayoría de esas Constituciones en el mundo contemplan el derecho de excepción ${ }^{5}$. Se erigen, en ese sentido, situaciones extraordinarias, imprevisibles y temporales para cuya atención el constituyente apuesta por la alteración del sistema de pesos y contrapesos, la separación funcional de los poderes del estado e, inclusive, la plena vigencia de los derechos fundamentales

Ese "sacrificio" se entiende justificado pues se motiva en la intención de regresar a un estado de cosas donde la "normalidad" haga viable el proyecto constitucional.

Los orígenes del derecho de excepción pueden trazarse en la dictadura romana de la antigüedad: una magistratura que se instituyó entre los siglos V a II A.C. y en la que uno de los cónsules romanos era declarado dictador por tiempo limitado -de máximo seis meses- ante sucesos extraordinarios de guerra y rebelión, por ejemplo (Bobbio, 1986: 167)

Pues bien, por su complejidad, este tema se trata, sin dudas, de uno de los más discutidos de la teoría general del estado y la ciencia política (Agamben, 2004), porque, entre otros, en el marco de esos regímenes se busca conciliar los conceptos de autoridad y libertad.

No se olvidan, en ese sentido y por ejemplo, las crispaciones que produjo -y que aún hoy produce- la teoría decisionista de Schmitt (1976) y su pueril justificación para reconocer una "dictadura soberana" a favor de Hitler, entendiendo como soberano a aquel que puede decidir sobre el estado de excepción y que no está sujeto al derecho, porque el derecho no puede regular lo que no puede prever.

A nivel histórico, Francia fue la primera nación moderna en introducir disposiciones constitucionales sobre el derecho de excepción, en 1795, y fue a partir de allí que su experiencia trascendió hasta llegar a países cuya cultura jurídica se vio fuertemente influenciada por la tradición francesa.

Así, por ejemplo, con la entronización de Napoleón Bonaparte como Rey de España -en 1808- se instauró el Estatuto de Bayona, en el que se incluían, entre muchas otras, disposiciones relativas al derecho de excepción (Bjørnskov \& Voigt, 2018). La estela de ese modelo fue seguida por muchas constituciones americanas: Argentina (1819), Chile (1822), Brasil (1824), Las Unidas del Río de la Plata (1824), Bolivia (1826), Perú (1826), Ecuador (1830), Uruguay (1830) y Venezuela (1830). ${ }^{6}$

fundación
4. Aunque esa afirmación no corresponde con la realidad pues de un análisis de las diferentes constituciones del mundo se ha hallado que aquellas suelen tener una vigencia aproximada de 19 años (Elkins, Ginsburg y Melton, 2009).

5. Para efectos prácticos del artículo, este término y el de "derecho de suspensión” se entenderán como sinónimos

6. A ese respecto, un apunte que merece la pena destacar es que, en todos esos casos, la inclusión de disposiciones relativas al derecho de excepción se dio en el marco de la creación de una constitución y que todos estos países se identifican con la tradición francesa del derecho civil-continental. 
Siguiendo en el tiempo, los estados de excepción fueron el denominador común durante la primera y segunda guerras mundiales, evento, este último, frente al cual se articuló, como respuesta, la revolución constitucional de la segunda mitad del siglo anterior. Este aspecto cobra relevancia como hipótesis explicativa del porqué el derecho de excepción responde a una lógica más bien belicista y no parece tener capacidad suficiente para afrontar sucesos de otro orden, como lo es una pandemia.

En todo caso, lo cierto es que el COVID-19 no es la primera -ni será la última- enfermedad que alcance el nivel de pandemia; no es todavía, ni siquiera, el padecimiento clínico más letal de la historia de la humanidad (Barra, 2020: 7-11) ${ }^{7}$. A partir de ello, resulta verdaderamente preocupante la frágil institucionalidad internacional y lo endeble de las respuestas ofrecidas por el derecho internacional, conforme lo han denunciado Von Bogdandy y Villarreal (2020).

Todo ello parece extraño en un estado de cosas como el actual, en el que 9 de cada 10 Estados en el mundo incluyen, en sus Constituciones vigentes, previsiones relativas a los regímenes de excepción (Bjørnskov \& Voigt, 2018). Estas figuras han sido, en algunas latitudes, una de las alternativas jurídicas más viables para enfrentar los embates de la mortal enfermedad, sin que, necesariamente y como lo apuntaron Ginsburg y Versteeg (2020), fueran el único tipo de respuestas de implementadas.

Es con base en las premisas anteriores que el presente texto tiene un doble objetivo. De un lado, analizar el marco constitucional de aquellos Estados latinoamericanos que, al declarar estados de excepción o emergencia, suspendieron o restringieron la vigencia plena de los derechos fundamentales en su territorio (de acuerdo con el artículo 27 de la Convención Americana sobre Derechos Humanos ${ }^{8}$ ). Son estos países, y no otros, los que integran la muestra del estudio.

De otra parte, se pretende brindar una introducción sobre los límites de los poderes de excepción de acuerdo con las exigencias del sistema interamericano de derechos humanos y la Corte Interamericana de Derechos Humanos ${ }^{9}$ para, posteriormente, explicar las medidas adoptadas por los Estados que integran la muestra, así como los controles políticos o jurisdiccionales de los poderes de emergencia que fueron accionados en cada uno de ellos.

\section{LOS REGÍMENES DE EXCEPCIÓN EN LAS CONSTITUCIONES LATINOAMERICANAS}

Los documentos constitucionales latinoamericanos incluidos en la muestra contemplan, en la mayoría de los casos, amplias regulaciones en relación con los regímenes de excepción que los poderes públicos pueden decretar bajo determinadas circunstancias de riesgo para las personas y las instituciones del país ${ }^{10}$. A ese respecto llama la atención cómo las trece constituciones examinadas presentan niveles de semejanzas y diferencias en materia de tales regímenes de excepción, tema que inaugurará el presente estudio.

7. Por ejemplo, la "peste negra" de mediados del siglo XIV mató a un número de personas cercano a la mitad de la población europea, continente donde se asentó por cinco años; la "gripe española”, por su parte, dejó un saldo mortal de aproximadamente 50 millones, entre 1918 y 1919.

8. En lo sucesivo CADH.

9. Corte IDH en lo sucesivo.

10. Los textos constitucionales consultados se encuentran a disposición, para su consulta, en la página web de la Organización de Estados Americanos, visible en URL: www.oas.org 


\section{Nomenclatura y tipología}

El primero de esos ámbitos de análisis comparativo tiene que ver con la nomenclatura que el poder constituyente asignó a esos estados de "anormalidad" y -derivado de ese primer punto- la singularidad o pluralidad en la tipología de esos regímenes a lo interno del ordenamiento jurídico.

Para una mayor claridad, el cuadro n. ${ }^{0} 1$ ofrece, gráficamente, la perspectiva completa respecto de ambos puntos:

\begin{tabular}{|c|c|}
\hline \multicolumn{2}{|c|}{ Cuadro n..$^{\circ}$. Regímenes de excepción en las constituciones de América Latina } \\
\hline País & Nomenclatura \\
\hline 1. Argentina & $\begin{array}{l}\text {-Estado de sitio } \\
\text {-Estado de emergencia } \\
\text {-Decreto de necesidad y urgencia }\end{array}$ \\
\hline 2. Bolivia & Estado de excepción \\
\hline 3. Chile & $\begin{array}{l}\text {-Estado de asamblea } \\
\text {-Estado de sitio } \\
\text {-Estado de catástrofe } \\
\text {-Estado de emergencia }\end{array}$ \\
\hline 4. Colombia & $\begin{array}{l}\text {-Estado de excepción } \\
\text {-Estado de conmoción interna } \\
\text {-Estado de emergencia }\end{array}$ \\
\hline 5. Ecuador & Estado de excepción \\
\hline 6. El Salvador & Estado de excepción \\
\hline 7. Guatemala & $\begin{array}{l}\text {-Estado de prevención } \\
\text {-Estado de alarma } \\
\text {-Estado de calamidad pública } \\
\text {-Estado de sitio } \\
\text {-Estado de guerra }\end{array}$ \\
\hline 8. Honduras & Estado de sitio \\
\hline 9. Panamá & Estado de urgencia \\
\hline 10. Paraguay & Estado de excepción \\
\hline 11. Perú & $\begin{array}{l}\text {-Estado de excepción } \\
\text {-Estado de emergencia } \\
\text {-Estado de sitio }\end{array}$ \\
\hline 12. República Dominicana & $\begin{array}{l}\text {-Estado de defensa } \\
\text {-Estado de conmoción interna } \\
\text {-Estado de emergencia }\end{array}$ \\
\hline 13. Surinam & $\begin{array}{l}\text {-Estado de sitio } \\
\text {-Estado de emergencia civil y militar }\end{array}$ \\
\hline
\end{tabular}

Fuente: elaboración propia con base en las constituciones consultadas en el sitio web www.oas.org

En cuanto a la nomenclatura empleada por las cláusulas constitucionales vigentes, las voces "Estado de sitio", "Estado de excepción" y "Estado de emergencia" son las opciones predilectas; la primera de ellas alude, como concepto propio de la jerga militar, al régimen de excepcionalidad que se opone como respuesta ante una agresión bélica o su amenaza, mientras que la segunda denota una interrupción en el curso regular de las vidas ordinarias de las personas y las instituciones del Estado (con especial referencia a los obstáculos, totales o parciales, para el pleno goce de los derechos fundamentales). 
Por último, el recurso al vocablo "estado de emergencia" se entiende derivado de la peligrosidad que implican, para el tejido social, las circunstancias de hecho que facultan su declaratoria. No en vano el diccionario de la Real Academia Española de la Lengua ${ }^{11}$ asegura que la aprobación de este tipo de institutos jurídicos es legítima ante el acaecimiento de "conflictos sociales y catástrofes naturales", entre otras circunstancias.

Amén de esa tripleta de términos, las constituciones de América Latina acuden, en menor medida, a otros rótulos semánticos: "Estado de defensa" "Estado de urgencia", "Estado de catástrofe", "Estado de conmoción interna", "Estado de alarma", "Estado de Asamblea", "Estado de prevención” y "Decreto de necesidad y urgencia".

Del cuadro n. $^{\circ} 1$ anterior también puede observarse que, en la muestra, una mayor proporción de los ordenamientos latinoamericanos de la muestra $(53,8 \%)$ prevé una pluralidad de modalidades de régimen de excepcionalidad, mientras que la restante $(46,2 \%)$ contempla un único instituto para atender situaciones de distinta índole.

Como característica distintiva, en este plano, debe apuntarse que cuando esos regímenes se contemplan en conjunto con otros, todos se ordenan en una prelación respecto de los hechos que justifican su declaratoria, la autoridad competente para su dictado y, naturalmente, los niveles de restricción o limitación de los derechos fundamentales. En cambio, al preverse como la "única alternativa" frente a multiplicidad de situaciones fácticas, la regulación constitucional se hace más uniforme en materia de su extensión, su procedimiento de aprobación y sus efectos.

\section{Presupuestos fácticos}

A propósito de un tema ya adelantado, los textos constitucionales de América Latina que fueron examinados prevén una amplia gama de presupuestos de hecho ante los cuales se hace viable la declaratoria del estado de excepción (o de alguno de ellos, cuando se cuente con distintas figuras). Cabe señalar que, en este punto, las Constituciones recurren a fórmulas muy genéricas, lo que les permite incluir, posteriormente, múltiples candidatos semánticos dentro del significante elegido. ${ }^{12}$

Así, la primera categoría de circunstancias que resulta más evocada en esos textos constitucionales es la situación de guerra ("agresión", "ataque", "invasión"), la que, además de contemplarse casi en todos los países de la muestra (12 de 13 países), se concibe eminentemente como una situación provenida del exterior ${ }^{13}$. Para referirse a conflictos o amenazas bélicas suscitadas desde el interior del propio país, en cambio, se echa mano del término "conmoción interna".

Otros de los vocablos a que se recurre en las cláusulas de las Constituciones examinadas son los de calamidad -"desgracia o infortunio que alcanza a muchas personas", según la RAE- (6 países ${ }^{14}$ y la voz compuesta "perturbación del orden público" (9 paíse $^{15}$ ). En cuanto a este último punto cabe destacar que, en algunos casos, la

11. RAE en lo sucesivo. Diccionario consultado en línea, visible en el URL: https://dle.rae.es.

12. Un ejemplo de regulación de límites más definidos lo ofrece la Constitución de Guatemala, pues en ella se avanzan situaciones más concretas respecto de las que se habilita la declaratoria de los estados de calamidad o sitio: actividades terroristas, sediciosas o de rebelión, sabotaje, incendio, secuestro o plagio, asesinato, ataques armados, entre otros.

13. Las constituciones de Chile, Ecuador y Perú son las únicas en habilitar la declaratoria del estado de excepcionalidad frente a una guerra en el "interior".

14. Chile, Colombia, Ecuador, El Salvador, Guatemala y Honduras.

15. Chile, Colombia, El Salvador, Guatemala, Honduras, Panamá, Perú, República Dominicana y Surinam. 
referencia al orden público se construye de modo más sencillo ("desórdenes") o de manera más compleja (refiriendo a un escenario de hecho cuyos efectos amenacen el orden público y la paz social).

En cuanto a la declaratoria del correspondiente régimen de excepcionalidad por el acontecimiento de fenómenos de la naturaleza, los textos consultados admiten mayoritariamente esa posibilidad (8 países ${ }^{16}$ ), definiéndola como "desastre" o "catástrofe" naturales, allí donde no se integra al significado de "calamidad".

A propósito del tema que se tratará en la siguiente sección de este artículo, llama la atención que únicamente las Constituciones de El Salvador y Honduras advierten, en su literalidad, la "epidemia" como único motivo sanitario habilitante para la aprobación de un régimen de excepcionalidad. Esto hace suponer, entonces, que los restantes países incluyen el contagio de una enfermedad de este tipo en alguno de los demás amplios términos a los que se hiciera referencia líneas atrás.

\section{Facultad de aprobación y procedimiento de control}

Uno de los aspectos con mayor uniformidad, en los documentos constitucionales de la muestra, lo constituye la asignación de competencia para la aprobación del régimen de excepción. Esto en la medida en que, casi en su totalidad (12 de 13 textos ${ }^{17}$ ), los países en estudio perfilan la declaratoria de los estados de excepción, sitio y emergencia -entre otros- a través de órdenes ejecutivas que, justamente por esa razón, se encargan al Poder Ejecutivo nacional.

Dentro de esa amplia proporción, a su vez, existen variantes en la incorporación -en esa labor- de otras autoridades ejecutivas además del Presidente: así, las Constituciones de Argentina, Colombia, Guatemala, Honduras, Panamá, y Perú consideran un sentido más amplio del Poder Ejecutivo, de ahí que, para la aprobación del decreto en cuestión, se requiera la voluntad afirmativa de los Ministros de Estado.

En cuanto a la participación del Poder Legislativo en el dictado del régimen de excepcionalidad, dos situaciones merecen especial atención. La primera de ellas, de importancia cuantitativa minoritaria, reside en el hecho de que las Constituciones de Argentina, El Salvador y Paraguay también reconocen a su Poder Legislativo la facultad para declarar esos estados de excepcionalidad. Se trata, en tales escenarios, de competencias que se encargan a los poderes Ejecutivo y Legislativo de forma diferenciada (según la situación o el tipo de régimen de excepcionalidad por aprobar).

La segunda de las situaciones, de capital importancia para el sistema de check and balances democrático, tiene que ver con los escenarios de diseño constitucional en los que la declaratoria de los indicados regímenes corresponde a la concurrencia de las voluntades legislativa y ejecutiva.

Con ello se refiere a los casos de los textos constitucionales de Argentina, Bolivia, Guatemala Honduras, Panamá, Paraguay, República Dominicana y Surinam, pues, en esos ordenamientos jurídicos, la declaratoria formulada por el Poder Ejecutivo requiere el oportuno beneplácito de las cámaras legislativas como condición necesaria de validez. 
Aunque las facultades de aprobación de los regímenes de excepcionalidad sean uniformes, como se dijo, lo cierto es que no puede decirse lo mismo en cuanto las funciones de control que se prevén para tales estados.

En ese sentido, no todos los textos constitucionales de la muestra establecen parámetros de control y supervisión para ser ejercidos durante alguno de los regímenes de excepcionalidad previstos. En esos escenarios figuran las constituciones de El Salvador, Honduras, Panamá y Perú.

En aquellos ordenamientos donde sí se reconocen potestades de control, las posibilidades varían en orden de importancia y las autoridades delegadas para la supervisión.

Respecto de la trascendencia del control, llaman la atención los casos de las Constituciones de Colombia, Ecuador y República Dominicana, donde se establece un control judicial preceptivo de las disposiciones y actos normativos emitidos durante el estado de excepcionalidad (incluida la constitucionalidad del decreto mismo en el que se apruebe ese régimen).

En un segundo escalafón respecto de la magnitud de ese control, las Constituciones de Bolivia, Guatemala y República Dominicana, por ejemplo, incluyen el deber del Presidente a rendir cuentas, ante el Poder Legislativo, de las acciones y medidas adoptadas a lo largo del periodo en que se mantuvieron vigentes los regímenes de excepción.

Finalmente, la Constitución de Surinam ofrece un caso único de atribuciones consultivas en el tema, pues en ese documento se encomienda a una autoridad administrativa (el Consejo Nacional de Seguridad) el trabajo conjunto con las autoridades gubernativas una vez que sea declarado el estado de sitio o de emergencia civil y militar.

\section{Suspensión o restricción de derechos fundamentales}

Un último punto en el análisis comparado lo constituye la previsión constitucional para permitir, como consecuencia de los regímenes de excepción, la suspensión o restricción de derechos fundamentales.

En ese aspecto, la tendencia mayoritaria (11 constituciones ${ }^{18}$ ) consiste en aceptar la suspensión parcial de las garantías constitucionales, indicando, en cada caso, un prontuario de derechos cuyo ejercicio pleno podrá interrumpirse en cada una de las situaciones.

En la acera contraria, las constituciones de Bolivia y Colombia no admiten que, durante la vigencia del régimen de excepcionalidad, se afecten los derechos y libertades de las personas. Ejemplo paradigmático de esta tendencia minoritaria lo constituye la Constitución colombiana, texto que señala, en su numeral 214.2, que en los estados de excepción: "no podrán suspenderse los derechos humanos ni las libertades fundamentales. En todo caso se respetarán las reglas del derecho internacional humanitario". 


\section{EL “DERECHO DE SUSPENSIÓN” EN EL CONTEXTO REGIONAL}

En atención a lo dispuesto en el artículo 27 de la CADH, todo Estado que ejercite el "derecho de suspensión" en casos de emergencia debe notificar de forma inmediata a los Estados parte de la Organización de Estados Americanos ${ }^{19}$. En esa comunicación, que se remitirá al Secretario General de la OEA, detallará los motivos que suscitan la suspensión de derechos y la fecha de vigencia de esta interrupción.

Al respecto, debe hacerse notar que esta obligación es exigible por el solo hecho de que un Estado pertenezca a la OEA y haya ratificado la CADH, sin importar si se encuentra sujeto o no a la jurisdicción de la Corte IDH.

Con base en el incremento exponencial de personas contagiadas de COVID-19 en el continente americano, diversos países de la región declararon estados de emergencia, estados de excepción, estados de catástrofe por calamidad pública o emergencia sanitaria nacional, todo ello a través de decretos presidenciales y otras disposiciones normativas de la más variada naturaleza jurídica.

Los estados en los que ocurrió esa declaratoria son: Argentina ${ }^{20}$, Bolivia ${ }^{21}$, Chi$\mathrm{le}^{22}$, Colombia ${ }^{23}$, Ecuador ${ }^{24}$, El Salvador ${ }^{25}$, Guatemala ${ }^{26}$, Honduras $^{27}$, Panamá ${ }^{28}$,

19. OEA en lo sucesivo.

20. Vid. Comunicado de la Misión Permanente de la República Argentina ante la Organización de los Estados Americanos (OEA 042) del 1 de abril de 2020. Disponible en:

http://www.oas.org/es/sla/ddi/docs/tratados_multilaterales_suspencion_garantias_Argentina_nota_No_422020.pdf (Último acceso: 22/06/2020)

21. Vid. Comunicado de la Misión Permanente del Estado Plurinacional de Bolivia ante la Organización de los Estados Americanos (MPB-OEA-NVo89-20) del 30 de marzo de 2020. Disponible en:

http://www.oas.org/es/sla/ddi/docs/tratados_multilaterales_suspencion_garantias_Bolivia_nota_No_NVo8920.pdf (Último acceso: 22/06/2020)

22. Vid. Comunicado de la Misión Permanente de Chile ante la Organización de los Estados Americanos (032/2020) del 26 de marzo de 2020. Disponible en:

http://www.oas.org/es/sla/ddi/docs/tratados multilaterales suspencion garantias Chile nota No 32-2020. pdf (Último acceso: 22/06/2020)

23. Vid. Comunicado de la Misión Permanente de Colombia ante la Organización de los Estados Americanos (424/2020) del 8 de abril de 2020. Disponible en:

http://www.oas.org/es/sla/ddi/docs/tratados_multilaterales_suspencion_garantias_Colombia_nota_MPCOEA_No_424-2020.pdf (Último acceso: 22/o6/2020)

24. Vid. Comunicado de la Misión Permanente del Ecuador ante la Organización de los Estados Americanos (4-2073/2020) del 17 de marzo de 2020. Disponible en:

http://www.oas.org/es/sla/ddi/docs/tratados_multilaterales_suspencion_garantias_Ecuador_nota_No_4-2073-2020.pdf (Último acceso: 22/06/2020)

25. Vid. Comunicado de la Misión Permanente de El Salvador ante la Organización de Estados Americanos (MPOEAOEA-024/2020) del 31 de marzo de 2020. Disponible en:

http://www.oas.org/es/sla/ddi/docs/tratados_multilaterales_suspencion_garantias_El_Salvador_MPOEAOEA-024-2020.pdf (Último acceso: 22/06/2020)

26. Vid. Comunicado de la Misión Permanente de Guatemala ante la Organización de los Estados Americanos (NV-OEA-M4-No.190-2020) del 26 de marzo de 2020. Disponible en:

http://www.oas.org/es/sla/ddi/docs/tratados_multilaterales suspencion garantias Guatemala nota No 1902020.pdf (Último acceso: 22/06/2020)

27. Vid. Comunicado de la Misión Permanente de Honduras ante la Organización de Estados Americanos (o57/ MPHOEA/2020) de 8 de abril de 2020. Disponible en:

fundación

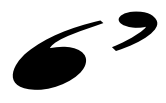

Manuel Giménez Abad

de Estudios Parlamentarios y delEstado Autonómico
http://www.oas.org/es/sla/ddi/docs/tratados_multilaterales_suspencion_garantias_Honduras_nota_No_572020.pdf (Último acceso: 22/06/2020)

28. Vid. Comunicado de la Misión Permanente de Panamá ante la Organización de Estados Americanos (PANAOEA-7-121) de 25 de marzo de 2020. Disponible en:

http://www.oas.org/es/sla/ddi/docs/tratados_multilaterales_suspencion_garantias_Panama_nota_No_7-1212020.pdf (Último acceso: 22/06/2020) 
Paraguay $^{29}$, Perú ${ }^{30}$, República Dominicana ${ }^{31}$ y Surinam ${ }^{32}$, pues fueron esos países los que remitieron las respectivas comunicaciones a la OEA notificando la suspensión de derechos convencionales.

Es importante anotar que, como efectivamente ha sucedido en algunos de esos casos, si un Estado extiende el período inicial de la suspensión de derechos convencionales o si amplía su alcance, se encuentra en la obligación de notificar sobre el particular al Secretariado de la OEA. ${ }^{33}$

Además, es necesario resaltar que otros instrumentos, como el Pacto de Derechos Civiles y Políticos de $1966^{34}$ (art.4.3), también imponen un deber de notificación, al Secretario General de las Naciones Unidas, cuando un Estado haga uso del derecho de suspensión. Esta precisión es relevante en la medida en que, por ejemplo, Venezuela, que adoptó un decreto de estado de alarma con motivo del COVID-19, denunció la CADH en 2012 y también la Carta de la OEA en 2017, sin perjuicio de lo cual se mantiene vinculado a las normas del PIDCP.

A propósito del derecho de suspensión de acuerdo con la CADH, debe aclararse que en comparación con otros instrumentos, como el PIDCP y el Convenio Europeo de Derechos Humanos, el artículo 27 de la CADH contiene un catálogo más amplio de derechos inderogables aún en caso de emergencia o excepción: a) el derecho al reconocimiento de la personalidad jurídica; b) el derecho a la vida; c) el derecho a la integridad personal; d) la prohibición de esclavitud y servidumbre; e) el principio de legalidad y de retroactividad; f) la libertad de conciencia y de religión; g) la protección de la familia; h) el derecho al nombre; i) los derechos del niño; j) el derecho a la nacionalidad; k) los derechos políticos; y, l) las garantías judiciales indispensables para su tutela.

La jurisprudencia de la Corte IDH exige, como presupuesto habilitante, que exista una amenaza inminente que no pueda resolverse por los medios previstos en el ordenamiento jurídico ordinario; amén de lo anterior, también ha establecido que la suspensión de derechos debe regirse por tres principios: proporcionalidad entre los medios y los objetivos propuestos, limitación geográfica y temporal y la prohibición de discriminación en la aplicación de las medidas adoptadas (Rodríguez Huerta, 2019: 835-849).

29. Vid. Comunicado de la Misión Permanente del Paraguay ante la Organización de Estados Americanos (292-20/ MPP/OEA) de 8 de mayo de 2020. Disponible en:

http://www.oas.org/es/sla/ddi/docs/tratados_multilaterales_suspencion_garantias_Paraguay_nota_292-20MPP-OEA.pdf (Último acceso: 22/06/2020)

30. Vid. Comunicado de la Representación Permanente del Perú ante la Organización de Estados Americanos (75-M/O45) de 30 de marzo de 2020. Disponible en:

http://www.oas.org/es/sla/ddi/docs/tratados_multilaterales_suspencion_garantias_Peru_nota_No_75-M-045-2020.pdf (Último acceso: 22/06/2020)

31. Vid. Comunicado de la Misión Permanente de la República Dominicana ante la Organización de Estados Americanos (MPRD-OEA 0300-2020) de 30 de marzo de 2020. Disponible en:

http://www.oas.org/es/sla/ddi/docs/tratados_multilaterales_suspencion_garantias_Republica_Dominicana_ nota_MPRD-OEA_0300-2020.pdf (Último acceso: 22/06/2020)

32. Vid. Comunicado de la Misión Permanente de Surinam ante la Organización de Estados Americanos (PVOAS/ SUR/191/20) de 4 de mayo de 2020. Disponible en:

http://www.oas.org/es/sla/ddi/docs/tratados_multilaterales_suspencion_garantias_Suriname_nota_No_PVOSA-SUR-191-20.pdf (Último acceso: 22/06/2020)

33. Pueden consultarse las comunicaciones más recientes en este sentido en:

http://www.oas.org/es/sla/ddi/tratados_multilaterales_interamericanos_acciones_recientes.asp (Último acceso: 22/06/2020)

34. PIDCP en lo sucesivo. 
En el mismo renglón, también cabe anotar que tanto la Comisión Interamericana de Derechos Humanos (2020) ${ }^{35}$ como la Corte IDH (2020) han emitido pronunciamientos sobre la pandemia y los derechos humanos en las Américas. ${ }^{36}$ Algunas referencias comunes que pueden extraerse al confrontar ambos criterios son:

1. Que la cooperación internacional y la acción conjunta, solidaria y transparente son fundamentales para solucionar los problemas actuales y futuros ocasionados por la pandemia;

2. Que todas las medidas adoptadas por los Estados deben obedecer a criterios científicos y a los principios de "absoluta necesidad, proporcionalidad y precaución";

3. Que los derechos económicos, sociales, culturales o ambientales deben ser garantizados sin discriminación y los Estados deben prestar especial protección a los grupos de mayor vulnerabilidad ${ }^{37}$;

4. En esa línea, la Corte IDH ha instado a los Estados a que "las trabajadoras y trabajadores de la salud deberán ser proveídos de los insumos, equipos, materiales e instrumentos que protejan su integridad, vida y salud, y que les permita desempeñar su labor en términos razonables de seguridad y calidad";

5. Que los Estados deben tomar "las acciones necesarias para prevenir casos de violencia de género y sexual; disponer de mecanismos seguros de denuncia directa e inmediata y reforzar la atención para las víctimas";

6. Que dadas las condiciones de hacinamiento que padecen las personas privadas de libertad "se torna necesario (...) disponer en forma racional y ordenada medidas alternativas a la privación de la libertad";

7. Que los Estados deben garantizar el acceso libre a la información; cuidar que el uso de la tecnología de monitoreo sea estrictamente la necesaria; garantizar el acceso a la justicia; la protección de defensores de los derechos humanos, entre otras medidas que deben ser observadas por todos los Estados parte.

\section{LA RESTRICCIÓN Y SUSPENSIÓN DE DERECHOS A PROPÓSITO DEL COVID-19: UNA BREVE REFERENCIA A LOS CASOS DE ESTUDIO EN EL CONTEXTO INTERAMERICANO}

La presente sección tiene como objeto exponer de forma resumida los elementos más relevantes sobre la respuesta institucional de los Estados en el marco de la pandemia del COVID-19. Para ello, la muestra ha sido seleccionada tomando en cuenta, como se dijo previamente, a aquellos Estados que ejercieron el derecho de suspensión y

fundación

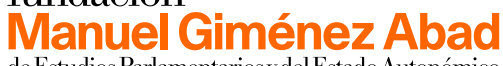

35. CIDH en lo sucesivo.

36. Cfr. CIDH. "Pandemia y Derechos Humanos en las Américas”. Resolución 1/20 del 10 de abril de 2020. Disponible: https://www.oas.org/es/cidh/decisiones/pdf/Resolucion-1-20-es.pdf. También, Corte IDH. Comunicado de prensa CP-27/2020 de 14 de abril de 2020. Disponible en: https://www.corteidh.or.cr/tablas/alerta/comunicado/ cp-27-2020.html (Último acceso: 22/06/2020)

37. “...Las personas mayores, las niñas y los niños, las personas con discapacidad, las personas migrantes, los refugiados, los apátridas, las personas privadas de la libertad, las personas LGBTI, las mujeres embarazadas o en período de post parto, las comunidades indígenas, las personas afrodescendientes, las personas que viven del trabajo informal, la población de barrios o zonas de habitación precaria, las personas en situación de calle, las personas en situación de pobreza, y el personal de los servicios de salud...”. (Corte IDH, 2020) 
así lo comunicaron a la OEA, a saber: Argentina, Bolivia, Chile, Colombia, Ecuador, El Salvador, Guatemala, Honduras, Panamá, Paraguay, Perú, República Dominicana y Surinam.

La exposición se centra, por tanto, en algunos pocos aspectos del contexto y el marco normativo de cada país, así como -en algunos casos- en el control político y judicial ejercido sobre las medidas adoptadas. Sirva de aclaración que el presente ensayo no pretende (ni está en capacidad de ofrecer) un análisis exhaustivo de cada elemento de la muestra, sino que busca, más bien, poner el acento en una perspectiva de conjunto.

\section{Argentina}

Argentina ha sido uno de los primeros países de la región en dar una respuesta pronta y eficaz al avance del COVID-19 ${ }^{38}$. Bajo esta circunstancia, y en el marco de las atribuciones conferidas por el art. 99 del texto constitucional, el Presidente de la República adoptó diversas medidas que se materializaron, en su mayoría, en la emisión de Decretos de Necesidad y Urgencia (DNU).

En la primera serie de medidas, el DNU 260/20 del 12 de marzo amplió la "emergencia pública en materia sanitaria”39 por el plazo de un año mientras que el DNU 287/2020 instituyó al Ministerio de Salud y al Jefe de Gabinete de Ministros como autoridades de aplicación.

Sin siquiera transcurrir una semana completa, el 19 de marzo, el Gobierno decretó el "aislamiento social, preventivo y obligatorio" 40 para todas las personas que residan o habiten en el territorio, limitando los desplazamientos a aquellos "mínimos e indispensables" a la vez que prohibió la realización de eventos sociales y suspendió toda actividad con excepción de las declaradas "esenciales" (DNU 297/2020) ${ }^{41}$. Para resguardar el cumplimiento de esas medidas en esa misma oportunidad se confirieron amplias atribuciones al Ministerio de Seguridad.

En este punto, cabe aclarar que el DNU que dispone el "aislamiento social, preventivo y obligatorio" fue declarado constitucional por resultar una medida "razonable y proporcional" para la defensa de la salud pública (Cámara Nacional en lo Criminal y Correccional "Kingston, Patricio s/ Habeas corpus", Causa n. ${ }^{0}$ 19.200/2020 del 21 de marzo de 2020).

En línea con lo expuesto, todas las acciones de prevención adoptadas por el ejecutivo en el marco de la emergencia sanitaria fueron ampliamente aceptadas y acatadas tanto por el Congreso como por el Poder Judicial nacional. Ambos poderes se adhirieron

38. Así lo ha destacado la Organización Mundial de la Salud (OMS) a través de un comunicado donde destacó que las medidas preventivas tomadas por el gobierno argentino "pueden cambiar la curva de contagios de coronavirus a algo más plana y lenta" (comunicado de la representante de la OMS en Argentina, Maureen Birmingham, dirigida al Presidente en fecha de 22 de marzo de 2020).

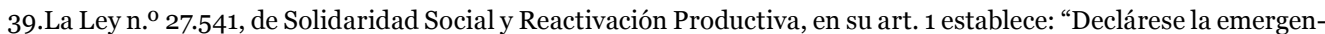
cia pública en materia económica, financiera, fiscal, administrativa, previsional, tarifaria, energética, sanitaria y social y delégase en el Poder Ejecutivo nacional, las facultades comprendidas en la presente ley en los términos del artículo 76 de la Constitución Nacional, con arreglo a las bases de delegación establecidas en el artículo 2, hasta el 31 de diciembre de 2020 ".

fundación

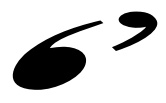

Manuel Giménez Abad

deEstudios Parlamentarios ydelEstado Autonómico
40. La medida de aislamiento social, preventivo y obligatorio se extiende en la región del Área Metropolitana de Buenos Aires hasta el 17 de julio de 2020 (DNU 576/2020).

41. Junto con esa medida crucial se adoptaron muchas otras decisiones complementarias como el cierre de fronteras (DNU 274/2020); ayudas económicas para diversos sectores y para las provincias más afectadas (Decreto $325 / 2020$ y Decisión administrativa 443/2020); prohibición de despidos (DNU 325/2020) y en materia procesal penal. 
a las disposiciones establecidas por el DNU 297/20, por lo que paralizaron parte de sus actividades (resolución n. ${ }^{\circ}$ o615/20 del Congreso de los Diputados ${ }^{42}$; resolución n..$^{\circ}$ SA 0448/20 del Senado de la Nación y acordada n..$^{0}$ 6/2020 de la Corte Suprema de Justicia de la Nación).

Finalmente, el día 29 de abril (es decir, casi un mes y medio después de mantener parcialmente paralizadas sus actividades) el Congreso aprobó el "protocolo de funcionamiento parlamentario remoto" a fin de reanudar las sesiones de forma "ordinaria". Cabe destacar que la modalidad "virtual" de las sesiones del Congreso fue previamente avalada por la Corte Suprema de Justicia por ser "un asunto que la Constitución defirió de forma privativa y exclusiva a su prudencia política" (CSJN, "Fernández de Kirchner, Cristina s/ acción declarativa de certeza", consid. 17, sentencia de 24 de abril de 2020).

\section{Bolivia}

El día 17 de marzo de 2020, el Gobierno de Bolivia declaró el "estado de emergencia sanitaria" mediante Decreto Supremo (D.S.) n. ${ }^{\circ}$ 4196; en el marco de esa declaratoria, el día 21 de marzo, la Presidencia dispuso como medida principal ${ }^{43}$ la "cuarentena total"44, con lo que únicamente se habilitaban desplazamientos mínimos e indispensables de una persona por familia en determinados días y franjas horarias. De esa condición se exceptuaron las fuerzas armadas, los servicios de salud, las entidades financieras y los servicios públicos y privados esenciales (D.S. n. ${ }^{\circ} 4199$ ).

Frente al incumplimiento de la cuarentena por parte de la población, y con base en lo previsto en el art. 172 de la Constitución boliviana, el Poder Ejecutivo "reforzó" las medidas en contra del contagio y propagación del COVID-19 al prohibir la circulación de personas menores de 18 años y mayores de 65 años, así como la organización de reuniones y el derecho de huelga (D.S. n. ${ }^{\circ}$ 4200).

Por otro lado, se restringió la libertad de expresión puesto que se declaró que aquellas personas que "desinformen o generen incertidumbre" a la población podrían ser sujetos de denuncia penal (D.S. n. ${ }^{\circ}$ 4231). Sin embargo, la polémica producida por esta "excesiva" medida -según lo señalara la propia Oficina del Alto Comisionado de las Naciones Unidas-45 llevó a su posterior derogación.

En el nuevo "paquete" de medidas también se endureció el control a cargo de las Fuerzas Policiales y Militares, quienes se vieron consecuentemente facultados a aplicar "medidas coercitivas" a fin de asegurar el mantenimiento del orden público, el Estado de Derecho, la paz social, la defensa de la vida y la salud (D.S. n. ${ }^{\circ} 4200$ ).

42. Cabe aclarar que la resolución n..$^{\circ}$ o615/20 del Congreso de los Diputados no especifica las áreas exceptuadas de la suspensión de actividades. Así, por ejemplo, la Comisión Bicameral Permanente, encargada de dictaminar acerca de la validez de los DNU (conforme lo prevé la Ley n. ${ }^{\circ}$ 26.122), continuó en funciones. Sin embargo, a la fecha solo sesionó una vez el día 28 de abril (https://www.diputados.gov.ar/comisiones/especiales/cbtlegislativo/ reuniones/videos/, última entrada el 19 de junio de 2020). En el caso del Poder Judicial, la acordada n. ${ }^{\circ}$ 6/2020 habilitó la "feria extraordinaria" respecto de todos los tribunales federales y nacionales, interviniendo únicamente en cuestiones penales, asuntos de familia y amparos. El día 10 de junio se dispuso la reactivación progresiva y escalonada de la actividad jurisdiccional.

43. Asimismo, se dictaron diversas disposiciones complementarias como el Plan de Emergencia de Apoyo al Empleo y Estabilidad Laboral y reactivación del empleo (D.S. n. ${ }^{\circ} 4216$ y 4272); la asignación presupuestaria de recursos adicionales (D.S. n. ${ }^{\circ}$ 4230); autorización extraordinaria al Ministerio de Relaciones Exteriores para realizar transferencias público-privadas durante el periodo de la emergencia sanitaria provocada por el Coronavirus (Decreto n. $\left.{ }^{\circ} 4323\right)$.

44. Mediante D.S. n. ${ }^{\circ} 4229$ se amplió la vigencia de la cuarentena "total” hasta el 31 de mayo de 2020 . A partir de esa fecha se establece la cuarentena "condicionada y dinámica" hasta el 30 de junio de 2020 (D. S. n..$^{\circ} 4245$ ). 
La Asamblea Legislativa aprobó las medidas implementadas por el Gobierno para la prevención, contención y tratamiento del COVID-19 y las revistió de "interés y prioridad nacional” (Ley n. ${ }^{\circ}$ 1293). Al igual que en muchos países de Latinoamérica, el Parlamento asumió un rol secundario dado que se limitó a ratificar las medidas impuestas por el gobierno y a legislar sobre cuestiones accidentales a la crisis sanitaria (v.gr. actividades de fomento -Leyes n. ${ }^{0} 1295 ; 1301 ; 1302 ; 1307-$; transferencia de bienes muebles -Leyes n. ${ }^{0} 1308$ y 1299-; y la postergación de las Elecciones Generales 2020 -Ley n. ${ }^{\circ}$ 1297-).

En lo que respecta a la actividad jurisdiccional, si bien la mayoría de las autoridades judiciales interrumpieron sus actividades por los efectos de la pandemia, lo cierto es que en el ámbito penal ocurrió un alto incremento de causas y condenas debido, principalmente, a las infracciones de la cuarentena. ${ }^{46}$

\section{Chile}

En el caso de Chile, la crisis del COVID-19 fue mitigada, en primer lugar, utilizando alertas sanitarias por parte del Ministerio de Salud. Sin embargo, el 18 de marzo de 2020, el Presidente declaró el "estado de excepción constitucional de catástrofe" en todo el territorio nacional por un término de 90 días ${ }^{47}$ (Decreto Supremo n. ${ }^{0} 104$ ). A esta declaratoria se sumó, entre otras medidas, el confinamiento "selectivo y dinámico $^{48}$ (Resolución del Ministerio de Salud n. ${ }^{0}$ 212), el cierre y control de fronteras, sanciones para los infectados de COVID-19 que incumplieran la cuarentena obligatoria, un toque de queda permanente y un control generalizado de identidad a cargo de los militares (Cofre, 2020).

En relación al marco constitucional de los poderes de emergencia, es necesario recordar que la Constitución (art. 39 a 45) se complementa con la Ley Orgánica Constitucional de los Estados de Excepción del año 1990 (Ley n. ${ }^{\circ}$ 18.415).

Así, en el marco de la coyuntura generada por la amplia propagación del virus a partir de marzo, el Congreso adaptó rápidamente sus procesos a fin de dar continuidad al trabajo legislativo y desarrollar, de esta manera, una modalidad de trabajo a distancia. De ese modo, el 25 de marzo se sancionó la Ley n.$^{\circ} 21.219$ que introduce, de manera transitoria, una reforma al texto constitucional que habilita al Congreso a sesionar por medios telemáticos "por el plazo de un año".

Esa norma, por su importancia frente a las condiciones actuales, sería calificada como un hito en la historia del Poder Legislativo, en las propias palabras del Senado de Chile (2020).

La pronta implementación de medios tecnológicos facilitó la intervención del Parlamento ante el impacto de la pandemia en un nutrido grupo de materias: la ejecución de un régimen de excepción para los procesos judiciales (Ley n. ${ }^{0}$ 21.226); medidas de ayuda económicas para sectores vulnerables (Ley n. ${ }^{\circ}$ 21.225); la concesión de indulto 
general (Ley $n .^{0}$ 21.228); la modificación del código penal para sancionar la inobservancia del aislamiento $\mathrm{u}$ otras medidas preventivas (Ley n. ${ }^{\circ}$ 21.240).

Para comprender el complejo escenario en Chile parece indispensable retroceder, brevemente, a octubre de 2019. En esta fecha -y como es de conocimiento público- inició una serie de revueltas ciudadanas por la subida de precio del tiquete del metro en la capital; frente a esas reacciones populares, el Presidente de la República declaró un estado de emergencia, situación que pareció incidir en el aumento de la represión: fue muchas y muy graves las denuncias sobre abusos en el uso de la fuerza y violaciones de derechos humanos a causa de la acción policial.

Este convulso episodio, que es un antecedente directo a la situación actual, culminó con un acuerdo nacional tendiente a adoptar un nuevo texto constitucional a efectos de reemplazar la vigente Constitución, que data de 1980 y, como legado del régimen de Pinochet, ha sido reiteradamente tildada de autoritaria, neoliberal e inequitativa.

Ahora bien, el desmedido impacto de la pandemia en suelo chileno llevó a que el cronograma para la implementación del nuevo documento constitucional fuera modificado, con lo que se postergó, por ende, el referéndum popular que permitiría la integración de la asamblea constituyente (Ley n. ${ }^{\circ} 21.221$ )

\section{Colombia}

En el caso colombiano, las actuaciones instrumentadas para atajar la pandemia fueron adoptadas inicialmente por el Ministro de Salud, los Gobernadores y los Alcaldes. Entre esas medidas se incluyeron los controles fronterizos, las restricciones de movilidad, las limitaciones al derecho de reunión y los toques de queda.

Adicionalmente, el Ministerio de Salud, por medio de Resolución n. ${ }^{\circ} 464$ de 2020, dispuso de manera temporal el confinamiento para cualquier persona mayor de 70 años por considerarlas población vulnerable ante el COVID-19. La actuación del gobierno nacional inició el día 17 de marzo de 2020, por medio del Decreto Legislativo n. ${ }^{\circ} 417$ de 2020, con el cual se declaró, en todo el territorio nacional, estado de emergencia social, económica y ecológica (Gaviria-Mira y Hoyos-Ceballos, 2020).

A este decreto de emergencia se suman más de 185 decretos de desarrollo por el cual se adoptan medidas para atajar la pandemia (Legis-ámbito jurídico, 2020). Para facilitar el control político de los decretos de emergencia el Congreso, después de casi un mes de parálisis, sesionó, debatió y votó por primera vez de manera virtual (Monterroza, 2020). Las sesiones virtuales estuvieron precedidas de una polémica política y jurídica, situación que depararía que, al igual que en Argentina, se impugnase ante la Corte Constitucional (El Espectador, 2020).

En Colombia, el control jurisdiccional de esas medidas está dividido entre la Corte Constitucional, que realiza un control automático cuando se trate de decretos legislativos en el marco del estado de excepción (arts. 215 y 241 de la Constitución de Colombia), y el Consejo de Estado, órgano que tiene la atribución de un control de legalidad oficioso cuando se trate de decretos expedidos en el marco del estado de excepción. En el caso del Decreto n. ${ }^{\circ} 417$ de 2020, la Corte Constitucional de Colombia declaró que el estado de emergencia era conforme con la Constitución.

fundación

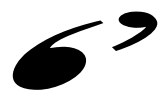

Manuel Giménez Abad

deEstudios Parlamentarios y del Estado Autonómico
Sin embargo, en la actualidad existe una controversia judicial sobre la restricción de derechos ya que mediante decretos ordinarios se han impuesto restricciones potentes a derechos fundamentales como la libre circulación (art. $24 \mathrm{CP}$ ) en conexidad con el derecho al trabajo (art. $25 \mathrm{CP}$ ), el derecho a la igualdad (art. $13 \mathrm{CP}$ ), el derecho al libre 
desarrollo de la personalidad (art. $16 \mathrm{CP}$ ), las libertades de reunión (art. $37 \mathrm{CP}$ ), religión (art. $19 \mathrm{CP}$ ), asociación (art. $38 \mathrm{CP}$ ), entre otros. Los decretos que están sometidos a un control jurisdiccional automático son los denominados decretos-legislativos, por lo que organizaciones como Dejusticia han requerido a la Corte Constitucional de Colombia que se pronuncie sobre esos instrumentos normativos (Dejusticia, 2020).

\section{Ecuador}

En el caso ecuatoriano, el Presidente de la República decretó el "estado de excepción"49 a nivel nacional el día 16 de marzo de 2020 (por decreto n. ${ }^{\circ}$ 1017), luego de que la Organización Mundial de la Salud declarará que el COVID-19 constituía una pandemia de alcance global. En el citado decreto se dispusieron varias medidas, entre las que se incluyeron, entre otras, la restricción de los derechos de libertad ambulatoria y de reunión, la vigilancia electrónica de pacientes infectados con el virus, la suspensión general de actividades laborales y la intervención activa de la policía y los militares en el control del orden público (Cervantes, 2020).

La Constitución de la República del Ecuador (2008) señala que la Asamblea Nacional puede revocar, en cualquier momento desde su expedición, los decretos ejecutivos de estado de excepción por razones de oportunidad. Sin embargo, este poder no ha sido ejercitado por el Legislativo ecuatoriano que, hasta el momento, se ha limitado a aprobar la denominada Ley de Apoyo Humanitario.

Esta normativa fue aprobada por una mayoría de 74 votos favorables -de 137 posiblese incluye diversas disposiciones en el ámbito económico, laboral, tributario y social, tales como: las rebajas en las pensiones educativas privadas, la suspensión temporal del desahucio en materia de inquilinato las rebajas en costo del servicio eléctrico; las facilidades de pago a la seguridad social, los créditos productivos para la reactivación económicas y la revisión de tasas de interés para la reactivación, entre otras ${ }^{50}$. A esto se agrega la aprobación de nuevas modalidades de contratación laboral por la emergencia y medidas especiales para el concurso de acreedores.

Importa señalar que, en la actualidad, la Asamblea Nacional de Ecuador sesiona virtualmente ${ }^{51}$ y que la Corte Constitucional valoró positivamente la constitucionalidad del estado de excepción.

No obstante, en los dictámenes n. ${ }^{0} 1-20-E E / 20^{a}$ del 25 de marzo de 2020 y n. ${ }^{\circ}$ $3-20-\mathrm{EE} / 2 \mathrm{O}^{\mathrm{a}}$ del 29 de junio de 2020 , dispuso sendos parámetros de aplicación que el ejecutivo debe observar durante la emergencia sanitaria a fin de garantizar los derechos constitucionales de las personas: la prohibición de suspender el normal funcionamiento del Estado, especialmente, el sistema de justicia y las garantías de los derechos constitucionales; la adopción protocolos biosanitarios para el trabajo y la necesidad de no exponer a usuarios y a funcionarios al virus; la imposibilidad de emplear el estado de emergencia para anular el derecho a la protesta pacífica;

fundación

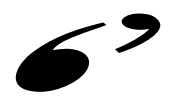

Manuel Giménez Abad

deEstudios Parlamentarios y del Estado Autonómico

49. Las circunstancias de la crisis sanitaria motivaron a que el presidente dicte un nuevo estado de excepción mediante Decreto $\mathrm{N}^{\circ} 1074$, del 15 de junio de 2020.

50. La ley de apoyo humanitario fue publicada en el Registro Oficial del lunes 22 de junio de 2020. Un resumen de las principales disposiciones de la ley se encuentra disponible en El Comercio, "Ley de Apoyo Humanitario se publicó en el Registro Oficial, ¿qué implica?”, accesible en: https://www.elcomercio.com/actualidad/registrooficial-vigencia-ley-humanitaria.html (último acceso: 08/07/2020).

51. Vid. Resolución CAL-2019-2021-213 del Consejo de Administración Legislativa de la Asamblea Nacional del Ecuador de fecha 18 de marzo de 2020. Disponible en: https://alertas.directoriolegislativo.org/wp-content/ uploads/2020/04/AN-SG-2020-0110-M_REGLAMENTO_IMPLEMENTACION_SESIONES_VIRTUALES_YTRABAJO__EMERGENTE.pdf 
la garantía de equipo sanitario para las fuerzas armadas y la policía nacional; y la prohibición de desviar fondos destinados a la salud y a la educación hacia otros fines, entre otros (Corte Constitucional del Ecuador, 2020). Tales precedentes son objeto de seguimiento actual por ese mismo órgano constitucional.

\section{El Salvador}

El 14 de marzo de 2020, la Asamblea Legislativa aprobó el Decreto Legislativo (D.L.) n. ${ }^{\circ}$ 593, en el que se declaró el "estado de emergencia nacional, estado de calamidad pública y desastre natural”. Esta disposición se complementaría con los D.L. n. ${ }^{\circ} 594$ y n. ${ }^{\circ} 611$ que regulan el "estado de excepción" (art. 29 de la Constitución) y restringen, temporalmente, los derechos a la libertad de tránsito y el derecho de reunión.

Las normas referenciadas han servido de base para que el Gobierno aprobara un amplio paquete de medidas para contener los efectos del virus, entre las que se destacan la "cuarentena total domiciliar" (Decreto ejecutivo n. ${ }^{\circ} 12$ ), el cierre de fronteras (Decreto ejecutivo $n .^{\circ}$ 5) y la restricción a la circulación (Decreto Ejecutivo n. ${ }^{0} 18$ ).

A diferencia de muchos países de la región, en el caso de El Salvador el Parlamento y el Ejecutivo han afrontado de manera conjunta y activa los avances de la pandemia ${ }^{52}$. No obstante, la hiperproducción y superposición normativa generó tensiones entre ambos poderes, por lo que algunas cuestiones fueron judicializadas y se encuentran a la espera de resolución (Controversias de inconstitucionalidad n..$^{\circ}$-20 y n. $.^{\circ} 3-20$ ).

A su vez, la Corte Suprema de Justicia (en concreto, la Sala de lo Constitucional) adoptó una postura muy crítica respecto de las medidas adoptadas en el marco del estado de emergencia, al punto de que llegó a suspender, cautelarmente y por alterar el orden de competencias constitucional, algunas normas dictadas por el Gobierno (Resolución n. ${ }^{\circ}$ 63-2020 de la Sala de lo Constitucional).

Finalmente, el tribunal salvadoreño también declaró la inconstitucionalidad del régimen de "excepción" adoptado por la Asamblea Legislativa por "omitir documentar y acreditar las razones que lo justificaban”, lo que implicaba una violación del art. 131 de la Constitución. De igual manera se pronunció sobre la inconstitucionalidad por "conexión" de todos los decretos ejecutivos que introducían restricciones al núcleo esencial de derechos fundamentales, pues estas disposiciones excedieron el orden de competencias constitucional (Resolución de Inconstitucionalidad n. ${ }^{\circ}$ 21-2020 de la Sala de lo Constitucional).

\section{Guatemala}

El día 5 de marzo del presente año, el Presidente de la República de Guatemala decretó el "estado de calamidad pública" por el plazo de 30 días ${ }^{53}$ (Decreto Gubernativo n. ${ }^{\circ}$ 5-2020).

Esa declaración fue reforzada con los Decretos n. ${ }^{0}$ 6-2020 y n. ${ }^{0}$ 7-2020, del 21 y 24 de marzo, respectivamente, en los que se establecieron prórrogas y medidas más restrictivas en cuanto a la libertad de locomoción (incluyendo orden de toque de queda 
nacional), el derecho de reunión y manifestación y el cierre de fronteras. Para velar por la correcta observancia de esas acciones, le fueron atribuidas amplias facultades a las Fuerzas de Seguridad Civil, las Fuerzas Armadas y al Ministerio de Salud Pública y Asistencia Social.

Por otro lado, el 30 de mayo, el gobierno declaró el "estado de sitio" en los municipios de Nahualá, Santa Catarina Ixtahuacán y Santa Lucía Utatlán en virtud de los "actos violentos y ataques armados derivados de disputas territoriales" (D.G. n. ${ }^{\circ}$ 10-2020).

A ese respecto, importa destacar que tanto la declaración de "calamidad pública" como el "estado de sitio" fueron aprobados y ratificados por el Congreso (Decretos Legislativos n. ${ }^{\circ}$ 8-2020, 9-2020, 22-2020 y 22-2020).

De igual manera, y con la finalidad de proteger a los guatemaltecos de los efectos causados por el COVID-19, el Parlamento sancionó el Decreto Legislativo n. ${ }^{0}$ 12-2020, en el que se establecieron una serie de medidas sanitarias, económicas, financieras y sociales para atender la crisis.

La norma referenciada ha sido fuertemente cuestionada pues algunas de las acciones en ella previstas (v.gr. los préstamos para políticos) resultan excesivas e injustificadas al parecer de algunas voces (Rodríguez y Marroquín, 2020; Hannah, 2020; Alexander, 2020; González, 2020).

A todo lo anterior hay que agregar que, en Guatemala, el Decreto Legislativo n. ${ }^{\circ}{ }^{15}$ 2020 garantiza la prestación de los servicios básicos a la población durante el estado de calamidad, espacio a propósito del cual se ha desencadenado una batalla entre los Poderes Ejecutivo (que vetó la Ley), Legislativo y las empresas prestatarias de dichos servicios. Este desencuentro motivó diversas impugnaciones ante la Corte de Constitucionalidad que a la fecha están pendientes de resolución.

\section{Honduras}

El 10 de febrero, el presidente de Honduras declaró el "estado de emergencia sanitaria" ${ }^{4}$ en todo el territorio nacional con el propósito de "fortalecer las acciones de prevención y control" (Decreto Ejecutivo n. ${ }^{\circ}$ PCM.005-2020).

En ese contexto, el día 15 de marzo, el Ejecutivo, amparado en los arts. 187 y 245 de la Constitución, decretó la restricción temporal de las siguientes garantías constitucionales: a) la libertad personal; b) la libertad de expresión; c) la libertad de asociación y reunión; d) la libertad de circulación (exceptuando a los funcionarios públicos); e) las garantías judiciales; $y, f$ ) la propiedad privada (Decreto Ejecutivo n. ${ }^{\circ}$ PCM-021-2020). ${ }^{55}$

Como respuesta a esa decisión, múltiples sectores sociales opusieron fuertes reclamos al Gobierno, razón por la que este decidió restablecer las garantías constitucionales vinculadas, únicamente, al ejercicio de la libertad de expresión y los derechos individuales (Decreto ejecutivo n. $\left.{ }^{\circ} \mathrm{PCM}-022-2020\right)$.

Las acciones comentadas fueron reforzadas con el cierre de fronteras y una orden de toque de queda "absoluto" en las ciudades más afectadas (v.gr. Distrito Central, La 
Ceiba y Choluteca). A su vez, para su estricto cumplimiento se previó que las Fuerzas Armadas y la Policía Nacional pudiera "detener a toda persona encontrada circulando fuera de las excepciones establecidas” (art. 6 Decreto Ejecutivo n. ${ }^{\circ}$ PCM-021-2020).

Todas las medidas de restricción de derechos dictadas por el Gobierno fueron ratificadas por el Congreso (Decreto Legislativo n. ${ }^{\circ}$ 32-2020), órgano que, complementariamente, sancionó diversas normas de orden económico (Decretos legislativos n. ${ }^{0}$ 29-2020 y n. ${ }^{\circ}$ 33-3030), entre las que se destaca la "Ley Especial de Aceleración Económica y Protección Social Frente a los Efectos del Coronavirus COVID-19”.

Esta última, valga reconocer, causó cierto grado de en razón de que habilitó contrataciones directas para obras públicas, bienes y servicios y, de igual manera, estableció una reasignación presupuestaria para cargar con los gastos de salud.

\section{Panamá}

En el caso de Panamá, el Gobierno de esa nación centroamericana anunció la restricción de ingreso al país, por parte de extranjeros, desde el 16 de marzo al tiempo que suspendía todos los vuelos internacionales por un plazo de treinta días. Aunado a lo anterior, se decretó el cierre temporal de establecimientos comerciales en todo el país, con excepción de productos y servicios de primera necesidad.

Entre las primeras medidas adoptadas de corte socioeconómico, el gobierno suspendió todas las cirugías no esenciales para aumentar, así, la capacidad de los hospitales públicos; en ese mismo renglón, dispuso la suspensión del cobro de los servicios básicos y el internet para aquellas personas que hubiesen perdido su empleo a propósito de la pandemia (Noticias ONU, 2020).

Adicionalmente, el actual gobierno panameño dispuso, por decreto $\mathrm{n} .^{\circ} 400$ de 27 de marzo de 2020, la creación del plan "Panamá Solidario", iniciativa que, dirigida a las personas en condición de mayor vulnerabilidad, consiste en la entrega de bolsas de comida, un bono solidario y un vale digital con dinero..$^{56}$

Entre las medidas restrictivas de los derechos destaca un toque de queda nocturno, con excepción de la capital y la provincia contigua de Panamá Oeste, donde está restringida la movilidad por género y a dos horas diarias de acuerdo con el número de identidad personal.

Por último, importa destacar que la Constitución de Panamá no prevé la existencia de un Tribunal Constitucional, sino que le asigna el control de constitucionalidad a la Corte Suprema de Justicia. De ese modo, el citado órgano puede dictaminar la inconstitucionalidad de los decretos, incluidos los de estado de urgencia, pero siempre previa demanda por parte de las personas o instituciones legitimadas.

Hasta el momento, la Corte Suprema de Justicia no ha adoptado resoluciones relevantes en relación al COVID-19 además de la suspensión y reactivación del servicio de justicia en el país. 


\section{Paraguay}

En Paraguay, el 26 de marzo de 2020, se promulgó la Ley n⿳0.6524 que declara "estado de emergencia" ante la pandemia del COVID-19, disposición normativa que establece la medidas con impacto en diversas áreas: los ámbitos laboral y de seguridad social, tributario, contratos privados, contratación pública, entre otras. ${ }^{57}$

Entre las acciones concretas que merecen ser destacadas se encuentran la autorización del teletrabajo en las relaciones laborales por dependencia, siempre que la naturaleza de la actividad lo permita; un subsidio de compensación del 25\% del salario mínimo a trabajadores autónomos o dependientes de pequeñas empresas que no coticen en la seguridad social; las compensaciones a los trabajadores que se vean afectados por el cese total de las actividades laborales; el mantenimiento de la seguridad social a los trabajadores con independencia del cumplimiento de las obligaciones patronales; la exención de consecuencias por el impago de alquileres siempre que se abone, al menos, el 40\% del canon respectivo; las facilidades en el acceso a crédito; y la autorización de contrataciones simplificadas y de emergencia en el ámbito público, entre otras (Ferrere, 2020).

De acuerdo con los artículos 259 y 260 de la Constitución de Paraguay, corresponde a la Corte Suprema de Justicia, y específicamente, a la Sala Constitucional, declarar la inconstitucionalidad de las leyes. En el caso de la citada ley n. ${ }^{\circ}$ 6524, que declara estado de emergencia en Paraguay, la Sala Constitucional podría, eventualmente, pronunciarse por vía de una acción de inconstitucionalidad.

\section{Perú}

El día 15 de marzo el Presidente de la República de Perú, en el marco de las atribuciones que le confiere el art. 137 de la Constitución ${ }^{58}$, decretó el "estado de emergencia nacional” por un plazo de 15 días $^{59}$. En este escenario, ordenó el "aislamiento social obligatorio" y la restricción de los derechos a la libertad y la seguridad personales, la inviolabilidad del domicilio y la libertad de reunión y de tránsito”, exceptuando la adquisición de bienes y servicios básicos (Decreto Supremo n. ${ }^{\circ}$ 044-2020).

Para asegurar el efectivo cumplimiento del confinamiento, el Gobierno decretó, entre otras medidas ${ }^{60}$, un toque de queda en casi todo el territorio (Decreto Supremo n. ${ }^{0}$ 046-2020) y otorgó amplias facultades de intervención a la Policía Nacional y las Fuerzas Armadas.

La premura con la que actuó el Ejecutivo frente a la propagación del virus, dejó al nuevo Congreso (cuya sesión inaugural tuvo lugar al día siguiente de la declaración de emergencia) en una situación peculiar: la primera Ley que aprobó el Parlamento

\footnotetext{
57. Ley n. ${ }^{\circ}$ 6524, por la que se declara el Estado de emergencia en todo el territorio de la República del Paraguay ante la pandemia declarada por la Organización Mundial de la Salud a causa del Covid-19 o coronavirus y se establecen medidas administrativas, fiscales y financieras. Disponible en: https://www.mtess.gov.py/documentos/ ley-65242020 (última consulta: 08/07/2020).

58. Tal como destacó la Comisión de la Verdad y Reconciliación (CVR) en su informe del año 2003 en Perú no existe una Ley que regule el estado de excepción (CVR (2003): Informe Final, Perú: 1980-2000).

59. El plazo del estado de emergencia fue ampliado hasta el día 30 de junio (Decreto Supremo n. ${ }^{\circ}$ 051-2020).

6o. El ejecutivo dictó un amplio paquete de medidas de emergencia entre las que se encuentran: ayudas, préstamos y asignación de partidas presupuestarias para mitigar los efectos económicos de la pandemia (Decretos de Urgencia n. ${ }^{\circ}$ 034-2020; n. ${ }^{\circ}$ 042-2020; n. ${ }^{\circ}$ 047-2020; n. ${ }^{\circ}$ 049-2020 y Decreto Supremo n. ${ }^{\circ}$ o83-2020); el suministro de productos para la salud (Decretos Supremos n. ${ }^{\circ}$ 015-2020 y n. ${ }^{\circ}$ 039-2020); la implementación de medidas laborales (Decreto Supremo n. ${ }^{\circ}$ 011-2020) y el cierre de fronteras.
} 
delegó facultades extraordinarias al Presidente para legislar sobre materias troncales, tales como: salud, política fiscal y tributaria, educación, seguridad ciudadana y procesal penal y penitenciaria (Leyes $n .^{0} 31011$ y n. ${ }^{0} 31020$ ), con lo que, claramente, auto limitó su competencia a materias periféricas. ${ }^{61}$

En ese marco, uno de los aspectos más cuestionados a labor legislativa fue la "innecesaria e impertinente" (Lovatón, 2020) promulgación de la Ley de Protección Policial (Ley n. ${ }^{\circ}$ 31012), la que, entre otras cuestiones, exime de responsabilidad penal a policías y militares que usen sus armas en defensa personal. Como era de esperar, fueron muchas las voces que se alzaron en contra ${ }^{62}$ y que advirtieron que la referida norma "abre espacios de impunidad" y "no se alinea con los estándares internacionales" (comunicado de prensa ONU, 1 de abril de 2020). Por tal razón, la ley en comentario fue impugnada ante el Tribunal Constitucional.

La crisis provocada por la pandemia también afectó seriamente la función judicial, que interrumpió toda su actividad pues únicamente garantizó una prestación "mínima" del servicio de justicia (en materia penal, habeas corpus y amparos) por la vía de los "juzgados de emergencia", autoridades creadas, especialmente, durante la vigencia de la emergencia nacional. ${ }^{63}$

\section{República Dominicana}

El 19 de marzo pasado, el Gobierno dominicano decretó "el estado de emergencia" por un plazo de 25 días en todo el territorio nacional ${ }^{64}$, esto "en virtud de la autorización otorgada por el Congreso Nacional" (Decreto n. ${ }^{0}$ 134-20 y Resolución del Congreso n. ${ }^{\circ}$ 62-20). Importa recordar, en ese sentido, que la previa autorización del Parlamento es uno de los requisitos previstos en el art. 262 de la Constitución y la Ley n. ${ }^{\circ}$ 21-18, que regula los estados de excepción. Conforme a ello, el decreto de emergencia expresamente obliga al Ejecutivo a rendir informes periódicos al Parlamento para dar seguimiento a las acciones adoptadas.

A su vez, durante el período de excepción se restringen las libertades de "tránsito, asociación y reunión" y se declara un "toque de queda" habilitando únicamente la circulación para la prestación de servicios básicos (Decreto n. $^{\circ} 135-20$ ). ${ }^{65}$

$\mathrm{Al}$ igual que en la mayoría de los sistemas de justicia de la región, se dispuso la suspensión de las labores presenciales, y se mantuvo en funcionamiento, únicamente,

\footnotetext{
61. Como por ejemplo las medidas de despliegue para control simultáneo durante la emergencia para el Covid-19 (Ley n..$\left.^{\circ} 31016\right)$; medidas para dinamizar la economía nacional (Ley n..$^{\circ} 31017$ ); suspensión de peajes (Ley n. ${ }^{\circ} 31018$ ); reconocimiento a los servidores públicos (Ley n.$^{\circ}$ 31021); que declara la intangibilidad de fondos del sistema privado de pensiones (Ley n. ${ }^{\circ}$ 31022); utilización de firma digital (Ley n. ${ }^{0}$ 31024). Información disponible en: http://www2. congreso.gob.pe/, última entrada 17/6/2020.

62. La CIDH expresó que "de conformidad con estándares interamericanos, leyes nacionales no deben contemplar excluyentes de responsabilidad que impidan investigar y sancionar responsables de violaciones de derechos humanos, en particular cuando perpetradores son agentes del Estado" (disponible en https://twitter.com/CIDH, última entrada 17/6/2020).

63. Resoluciones Administrativas del Poder Judicial n. ${ }^{o}$ 103-2020; n. ${ }^{\circ}$ 115-2020 y n. ${ }^{\circ}$ oooo61-2020, así como acuerdos del Consejo Ejecutivo del Poder Judicial n..$^{\circ} 480$ y n. ${ }^{\circ} 481-2020$.

64. Todas las prórrogas del estado de emergencia (Decreto n. ${ }^{\circ} 148-20$; Decreto n. $.^{\circ} 153-20$ Decreto n. ${ }^{\circ}$ 213-20) fueron aprobadas previamente por el Congreso (Resoluciones n. ${ }^{0} 160-20$ y n. ${ }^{\circ} 65^{-20}$ ).

65. El Gobierno también dispuso la suspensión de cómputos de los plazos y términos de los procedimientos administrativos (Decreto n. ${ }^{\circ}$ 137-20); creación del Fondo de Asistencia Solidaria al Empleado (FASE) (Decreto n. ${ }^{\circ}$ 143-20); creación de la Comisión de Alto Nivel para la Prevención y Control del Coronavirus (Decreto Núm.132-20); declaración de emergencia en las compras y contrataciones de bienes y servicios indispensables para la ejecución
} de iniciativas para hacer frente al (COVID-19) (Decreto n. $\left.{ }^{0} 133-20\right)$, entre otras medidas.

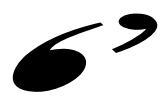


la Jurisdicción Penal y los recursos de amparo y hábeas corpus (actas de sesiones extraordinarias n. ${ }^{\circ}$ 01-2020 y n. ${ }^{\circ}$ 02-2020 del Poder Judicial).

\section{Surinam}

En el caso de Surinam -el país más pequeño de América del Sur y colonia de los Países Bajos hasta 1975-, el estado de emergencia civil fue declarado por el Presidente el día 8 de abril de 2020 y así ratificado por el Congreso, un día después, mediante la implementación de la Ley de Condición Excepcional COVID-19. El plazo de duración de ese régimen de excepcionalidad será de tres meses, de acuerdo con el texto constitucional y la citada ley, salvo que ese término sea prolongado, hasta por una única vez, por el propio Poder Legislativo.

Entre las medidas adoptadas para atajar la pandemia se incluyen: la restricción de la libertad ambulatoria de las personas; la designación a toda propiedad no residencial o comercial como de uso público a efectos de instalar hospitales de emergencia y estaciones de cuarentena temporal; la creación de un Equipo para la gestión de la Crisis del COVID-19 con capacidad de aconsejar al presidente respecto de nuevas medidas para afrontar la emergencia; la creación de un fondo económico de emergencia; y la obligación de los medios de comunicación de transmitir información del gobierno relacionada al COVID-19, entre otras.

A pesar de que en este momento se mantenía vigente el referido estado de emergencia, las legislativas programadas para el pasado mes de mayo del año en curso se celebraron, de manera efectiva, en ese país caribeño, todo ello bajo la supervisión de la OEA y la Comunidad del Caribe.

\section{APRECIACIONES FINALES A MODO DE CONCLUSIÓN}

A la fecha, trece estados latinoamericanos suscriptores de la CADH han ejercido el denominado "derecho de suspensión" previsto en el artículo 27 del tratado. Para dimensionar esa referencia importa apuntar que, actualmente, el también llamado Pacto de San José cuenta con veinticinco Estados parte. En ese sentido, el estudio se enfocó en la muestra de países que, en ese universo de elementos, declararon los estados de excepción o emergencia y cumplieron el deber de notificar esa situación al Secretario General de la OEA.

Como primer corolario despunta el hecho de que, a pesar del alto nivel de contagios en sus territorios, ni Brasil ni México hayan ejercitado el referido "derecho de excepción".

Este apunte se explica en la consideración de que, en la lucha contra el COVID-19, la estrategia adoptada por la gran mayoría de países ha incluido distintas alternativas de reacción (el uso de legislación preexistente y la expedición de legislación específica), sin que exista, a este momento, un método de uso más frecuente que el recurso a los regímenes de excepción.

Una posible explicación para que ciertos Estados se mantengan reacios a utilizar los poderes de excepción tiene que ver con la larga historia de abusos vinculados a esta institución, en América latina, por parte de regímenes autoritarios.

fundación

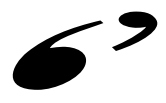

Manuel Giménez Abad

deEstudios Parlamentarios ydelEstado Autonómico
Importa destacar, en esa línea, que la apertura constitucional al derecho internacional de los derechos humanos ha sintetizado un ius commune latinoamericano que marca estándares en el uso de los poderes de excepción: deben ser limitados temporal y geográficamente, estrictamente proporcionales en las medidas que se adopten, no 
incluir sesgos discriminatorios y respetar los derechos y las garantías que no pueden ser suspendidas en ningún caso.

A nivel constitucional puede verificarse una interesante diversidad en cuanto a los regímenes de excepción en temas como singularidad o pluralidad de la tipología, presupuestos fácticos, autoridades a cargo de su declaratoria, mecanismos de control y niveles de afectación a los derechos fundamentales de los ciudadanos de estos Estados. Todo ese crisol de diferencias resulta natural en un espacio, como el Latinoamericano, en el que la diversidad política y de diseños institucionales ha estado, siempre, a la orden del día.

Por último, en cuanto a las medidas implementadas para afrontar la pandemia en curso, se tienen como denominadores comunes, en la muestra elegida, el confinamiento domiciliario, el cierre de fronteras y la suspensión de actividades laborales.

Otros casos más complejos se relacionan con la suspensión del derecho de asociación, la huelga y la libertad de expresión, acciones que son difícilmente justificables aún en el contexto actual y que han sido motivo de pronunciamientos jurisdiccionales en varios países.

La experiencia histórica brinda motivos suficientes para desconfiar del derecho de excepción en América latina y nos invita a rechazar su uso permanente bajo la excusa de la prolongada duración de la pandemia, por ello no resulta descabellado pensar que un marco jurídico permanente y la cooperación internacional puedan ser las claves futuras para resolver un problema cuyos amplios y nocivos efectos pone en entredicho el bienestar de la especie humana en conjunto. 


\section{BIBLIOGRAFÍA}

- AGAMBEN, Giorgio (2004): Estado de excepción, Buenos Aires, Adriana Hidalgo editora.

- AHERN, Hannah. (2020): Restricción de derechos civiles y políticos para combatir la pandemia del COVID 19 en Guatemala. http://dplf.org/sites/default/ files/guatemala_hannah_ahern.pdf.

- BARRA, Rodolfo (2020): “Prólogo”, pp. 7-12. Barra, Rodolfo y Plaza, Martín (coords.), Emergencia sanitaria global: su impacto en las instituciones jurídicas. Ediciones RAP, Buenos Aires.

- BOBBIO, Norberto (1986): El futuro de la democracia, Plaza Janés Editores.

- BOGDANDY, Armin \& VILLAREAL, Pedro (2020): "International law on pandemic response: a first stocktaking in light of the coronavirus crisis". MPIL research papers series No. 2020-07, pp. 1-26.

- BJØRNSKOV, Christian \& VOIGT, Stefan (2018): The architecture of emergency constitutions, International Journal of Constitutional Law, Volume 16, Issue 1, pp.101-127.

- CAO, Christian A. (2020): ¿Estado de sitio? No por el momento. Revista Asociación argentina de Derecho Constitucional, Nro. SE 1.

- CAO, Christian A. (2020): La carrera para habilitar actividades "esenciales". Revista Asociación argentina de Derecho Constitucional, Nro. SE 1.

- CARRASCO GIL, Andrea. (2020): Una transformación latente y otra pendiente: el Poder Judicial frente al COVID-19. Recuperado de https://idehpucp.pucp.edu. pe/notas-informativas/una-transformacion-latente-y-otra-pendiente-el-poderjudicial-frente-al-covid19/.

- CERVANTES, Andrés (9 de Julio de 2020): "Ecuador - Constitutionalism and Covid-19", VerfBlog, (2020/5/o9), https://www.verfassungsblog.de/ecuadorconstitutionalism-and-covid-19/

- COFRE, Leonardo (9 de Julio de 2020):Chile and COVID-19: A Constitutional Authoritarian Temptation, VerfBlog, (2020/5/19), https://www.verfassungsblog. de/chile-and-covid-19-a-constitutional-authoritarian-temptation/

- COMISIÓN INTERAMERICANA DE DERECHOS HUMANOS (2020): Pandemia y Derechos Humanos en las Américas. Resolución 1/20 del 10 de abril de 2020. https://www.oas.org/es/cidh/decisiones/pdf/Resolucion-1-20-es.pdf.

- COMISIÓN DE LA VERDAD Y RECONCILIACIÓN. (2003): Informe Final Perú: Lima, tomos I, III, VI, VIII y IX.

- CONSEJO DE ADMINISTRACIÓN LEGISLATIVA - Asamblea Nacional de Ecuador (9 de julio de 2020): Resolución CAL-2019-2021-213 del Consejo de Administración Legislativa de la Asamblea Nacional del Ecuador de fecha 18 de marzo de 2020. https://alertas.directoriolegislativo.org/wp-content/ uploads/2020/04/AN-SG-2020-0110-M_REGLAMENTO_IMPLEMENTACION_ SESIONES_VIRTUALES_Y__TRABAJO-_EMERGENTE.pdf

- CORTE CONSTITUCIONAL DEL ECUADOR (2020): Dictamen n. ${ }^{\circ} 1-20-E E / 20^{a}$ del 25 de marzo de 2020, www.corteconstitucional.gob.ec

- CORTE CONSTITUCIONAL DEL ECUADOR (2020): n. ${ }^{\circ} 3-20-E E / 20^{a}$ del 29 de junio de 2020, www.corteconstitucional.gob.ec

- CORTE INTERAMERICANA DE DERECHOS HUMANOS (2020): Comunicado de prensa CP-27/2020 de 14 de abril de 2020. https://www.corteidh.or.cr/tablas/ alerta/comunicado/cp-27-2020.html 
- CORTÉS-ARBELÁEZ, Alejandro. (2 de mayo de 2020): Pandemic and States of Emergency: A Comparative Perspective. Icconect. http://www.iconnectblog. com/2020/05/pandemic-and-states-of-emergency-comparative-perspective/.

- DEJUSTICIA (2020): "Solicitud de avocar conocimiento de oficio Asunto: Control de constitucionalidad automático a los Decretos 457 del 22 de marzo de 2020, 531 del 8 de abril y 536 de 11 abril de 2020, emitidos en razón y durante la vigencia del estado de emergencia económica, social y ambiental". 22 de abril de 2020. https://www.dejusticia.org/wp-content/uploads/2020/04/MemorialCorte-Constitucional.pdf

- EL COMERCIO (8 de julio de 2020): "Ley de Apoyo Humanitario se publicó en el Registro Oficial, ¿̇qué implica?”, https://www.elcomercio.com/actualidad/ registro-oficial-vigencia-ley-humanitaria.html

- EL ESPECTADOR (9 de julio de 2020): "La Cámara pide a la Corte Constitucional que se pronuncie sobre las sesiones virtuales".https://www.elespectador.com/ noticias/politica/la-camara-pide-la-corte-constitucional-que-se-pronunciesobre-las-sesiones-virtuales-articulo-916215/

- ELKINS, Zachary, GINSBURG, Tom y MELTON, James (2009): The Endurance of National Constitutions, Cambridge, Cambridge University Press.

- FERRERE (2020): "Paraguay: COVID-19 - Declaración de estado de emergencia y nuevas medidas adoptadas por el gobierno". https://www.ferrere.com/es/ novedades/paraguay-covid-19-declaracion-de-estado-de-emergencia-y-nuevasmedidas-adoptadas-por-el-gobierno/

- GARGARELLA, Roberto. (1 de mayo de 2020): The fight against Covid-19 in Argentina: Executive vs. Legislative Branch. Verfassungsblog. https:// verfassungsblog.de/the-fight-against-covid-19-in-argentina-executive-vslegislative-branch/.

- GAVIRIA-MIRA, Julián; HOYOS-CEBALLOS, Esteban (9 de Julio de 2020): Pandemic and Executive Powers in Colombia: A Problem and a Modest Proposal, VerfBlog, (2020/4/17), https://www.verfassungsblog.de/pandemic-andexecutive-powers-in-colombia-a-problem-and-a-modest-proposal/

- GINSBURG, Tom \& VERSTEEG, Mila (9 de Julio de 2020): States of Emergencies: Part I, Harvard Law Review blog. https://blog.harvardlawreview. org/states-of-emergencies-part-i/

- GONZÁLEZ, José. (28 de abril de 2020): Challenges Beyond Public HealthGuatemala and the Covid-19 Crisis. Verfassungsblog. https://verfassungsblog.de/ challenges-beyond-public-health-guatemala-and-the-covid-19-crisis/\#primary_ menu_sandwich.

- JARAB, Jan. (2020): Declaración pública sobre la promulgación de la Ley $\mathrm{N}^{\circ}$ 31012. Oficina de las Naciones Unidas para los Derechos Humanos en América del Sur. Recuperado de https://news.un.org/es/story/2020/04/1472172.

- LOVATÓN, David. (26 de Abril de 2020): Quarantine, State of Emergency, State of Enforcement, and the Pandemic in Perú. Verfassungsblog https:// verfassungsblog.de/quarantine-state-of-emergency-state-of-enforcement-andthe-pandemic-in-peru/.

- LEGIS-ÁMBITO JURÍDICO (6 de julio de 2020): Observatorio Jurídico Coronavirus (Covid-19) https://www.ambitojuridico.com/observatorio-juridicocoronavirus-covid-19\#tema10

fundación

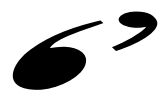

Manuel Giménez Abad

de Estudios Parlamentarios ydelEstado Autonómico
- MONTERROZA, Vanessa (9 de julio de 2020): La constitucionalidad de las sesiones virtuales del Congreso de la República, Blog de la Revista Derecho del Estado, Bogotá,https://revistaderechoestado.uexternado.edu.co/2020/04/03/laconstitucionalidad-de-las-sesiones-virtuales-del-congreso-de-la-republica/ 
- NOTICIAS ONU (8 de julio de 2020): "Panamá va un paso por delante en la respuesta al coronavirus”, disponible en URL: https://news.un.org/es/ story/2020/03/1471462

- ORGANIZACIÓN DE ESTADOS AMERICANOS (9 de julio de 2020), WWW.oas.org

- ORGANIZACIÓN DE ESTADOS AMERICANOS ( 9 de julio de 2020), Acciones recientes en materia de Tratados Multilaterales http://www.oas.org/es/ sla/ddi/tratados_multilaterales_interamericanos_acciones_recientes.asp

- REAL ACADEMIA DE LA LENGUA ESPAÑOLA (9 de julio de 2020), https://dle.rae.es

- REPÚBLICA DE PANAMÁ, Ministerio de la Presidencia (2020): Decreto ejecutivo No.400 de 27 de marzo de 2020 publicado en la Gaceta Oficial Digital del 3 de abril de 2020. https://www.gacetaoficial.gob.pa/pdfTemp/28995_A/78115.pdf

- REPÚBLICA DE PARAGUAY (2020): Ley n. ${ }^{\circ}$ 6524, por la que se declara el Estado de emergencia en todo el territorio de la República del Paraguay ante la pandemia declarada por la Organización Mundial de la Salud a causa del Covid-19 o coronavirus y se establecen medidas administrativas, fiscales y financieras. https://www.mtess.gov.py/documentos/ley-65242020

- RODRÍGUEZ HUERTA, Gabriela (2019): "Artículo 27. Suspensión de garantías", pp. 835-849. Convención Americana sobre Derechos Humanos. Comentario. Steiner, Christian y Fuchs, Marie-Christine (Eds.), Bogotá, Konrad Adenauer Stiftung, 2nda edición.

- RODRÍGUEZ, Francisco y MARROQUÍN, Ricardo. (25 de marzo de 2020): Préstamos fáciles para políticos, colegiaturas sin multas, y salarios: La Ley contra el Coronavirus. Plaza Pública. https://www.plazapublica.com.gt/content/ prestamos-faciles-para-politicos-colegiaturas-sin-multas-y-salarios-la-leycontra.

- SÁENZ J., Luis F. (2006): La regulación de los estados de excepción en Guatemala y la necesidad de reforma de la ley de Orden Público que los contiene, para su congruencia con la normativa de la Constitución Política de la República. Anuario de Derecho Constitucional Latinoamericano, Tomo I, pp. 204-227.

- SALOMÓN, Elisabeth. (11 de junio de 2020): Seguridad vs. apoyo social: respuestas estatales a la pandemia. Pontificia Universidad Católica de Perú. https://puntoedu.pucp.edu.pe/opinion/elizabeth-salmon-respuestas-estatales-ala-pandemia/

- SCHMITT, Carl (1976): The Concept of the Political. traducción e introducción de George Schwab, Nueva Jersey, Rutgers University Press.

- SEGOVIA, Alexander (2020): Las respuestas de Centroamérica ante la pandemia: distintas prioridades y apuestas riesgosas. Recuperado de https://www. fundacioncarolina.es/wp-content/uploads/2020/04/AC-14-2020.pdf.

- SENADO DE CHILE (8 de julio de 2020): Comunicado de prensa https://www.senado.cl/parlamentarios-podran-votar-a-distancia-ya-es-ley/ senado/2020-03-23/221036.html

- SILES, Abraham. (2017): Problemática constitucional del estado de emergencia en Perú: algunas cuestiones fundamentales, Centro de Estudios Constitucionales de Chile, $\mathrm{N}^{\mathrm{O}}$ 2, pp. 123-166.

- YLARRI, Juan S. (2020): Los alcances del control judicial sobre las normas adoptadas para enfrentar el Coronavirus. Revista Asociación argentina de Derecho Constitucional Nro. SE 1. 


\section{Otras fuentes de consulta}

Misiones permanentes ante la OEA:

- República de Argentina (2020): Comunicado OEA 042 del 1 de abril de 2020. Recuperado de:

http://www.oas.org/es/sla/ddi/docs/tratados_multilaterales_suspencion_ garantias_Argentina_nota_No_42-2020.pdf

- Estado Plurinacional de Bolivia (2020): Comunicado MPB-OEA-NVo89-20 del 30 de marzo de 2020. Recuperado de:

http://www.oas.org/es/sla/ddi/docs/tratados_multilaterales_suspencion_ garantias_Bolivia_nota_No_NVo89-20.pdf

- República de Chile (2020): Comunicado 032/2020 del 26 de marzo de 2020. Recuperado de:

http://www.oas.org/es/sla/ddi/docs/tratados_multilaterales_suspencion_ garantias_Chile_nota_No_32-2020.pdf

- República de Colombia (2020): Comunicado 424/2020 del 8 de abril de 2020. Recuperado de:

http://www.oas.org/es/sla/ddi/docs/tratados_multilaterales_suspencion_ garantias_Colombia_nota_MPC-OEA_No_424-2020.pdf

- República del Ecuador (2020): Comunicado 4-2-073/2020 del 17 de marzo de 2020. Recuperado de:

http://www.oas.org/es/sla/ddi/docs/tratados_multilaterales_suspencion_ garantias_Ecuador_nota_No_4-2-073-2020.pdf

- República de El Salvador (2020): Comunicado MPOEA-OEA-024/2020 del 31 de marzo de 2020. Recuperado de:

http://www.oas.org/es/sla/ddi/docs/tratados_multilaterales_suspencion_ garantias_El_Salvador_MPOEA-OEA-024-2020.pdf

- República de Guatemala (2002): Comunicado NV-OEA-M4-No.190-2020 del 26 de marzo de 2020. Recuperado de:

http://www.oas.org/es/sla/ddi/docs/tratados_multilaterales_suspencion_ garantias_Guatemala_nota_No_190-2020.pdf

- República de Honduras (2020): Comunicado 057/MPHOEA/2020 de 8 de abril de 2020. Recuperado de:

http://www.oas.org/es/sla/ddi/docs/tratados_multilaterales_suspencion_ garantias_Honduras_nota_No_57-2020.pdf

- República de Panamá (2020): Comunicado PANA-OEA-7-121 de 25 de marzo de 2020. Recuperado de:

http://www.oas.org/es/sla/ddi/docs/tratados_multilaterales_suspencion_ garantias_Panama_nota_No_7-121-2020.pdf

- República del Paraguay (2020): Comunicado 292-20/MPP/OEA de 8 de mayo de 2020. Recuperado de:

http://www.oas.org/es/sla/ddi/docs/tratados_multilaterales_suspencion_ garantias_Paraguay_nota_292-20-MPP-OEA.pdf

fundación

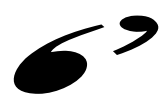

Manuel Giménez Abad deEstudios Parlamentarios y del Estado Autonómico
- República del Perú (2020): Comunicado 7-5-M/045 de 30 de marzo de 2020. Recuperado de:

http://www.oas.org/es/sla/ddi/docs/tratados_multilaterales_suspencion_ garantias_Peru_nota_No_7-5-M-045-2020.pdf 
- República Dominicana (2020): Comunicado MPRD-OEA 0300-2020 de 30 de marzo de 2020. Recuperado de:

http://www.oas.org/es/sla/ddi/docs/tratados_multilaterales_suspencion_ garantias_Republica_Dominicana_nota_MPRD-OEA_0300-2020.pdf

- República de Surinam (2020): Comunicado PVOAS/SUR/191/20 de 4 de mayo de 2020. Recuperado de:

http://www.oas.org/es/sla/ddi/docs/tratados_multilaterales_suspencion_ garantias_Suriname_nota_No_PVOSA-SUR-191-20.pdf< 